\title{
EFFECTIVENESS OF TRANSVERSUS ABDOMINIS PLANE BLOCK FOR POSTOPERATIVE ANALGESIA IN OBSTETRIC CASES UNDERGOING CAESAREAN SECTION
}

\author{
Pradhan $R^{1^{*}}$, Rajbanshi $L K^{1}$, Arjyal $B^{1}$, Mishra $S K^{2}$, Pokharel $H P^{3}$, Khanal $K^{4}$
}

\begin{abstract}
Affiliation
1. Lecturer, Anaesthesia and Critical Care, Birat Medical College and Teaching Hospital, Nepal

2. Lecturer, Obstetrics and Gynaecology, Birat Medical College and Teaching Hospital, Nepal

3. Professor, Obstetrics and Gynaecology, Birat Medical College and Teaching Hospital, Nepal

4. Consultant, Anaesthesia and Critical Care, Birat Medical College and Teaching Hospital, Nepal
\end{abstract}

\section{ARTICLE INFO}

Received : 02 May, 2019

Accepted : 14 August, 2019

Published : 31 August, 2019

(c) Authors retain copyright and grant the journal right of first publication with the work simultaneously licensed under Creative Commons Attribution License CC - BY 4.0 that allows others to share the work with an acknowledgment of the work's authorship and initial publication in this journal.

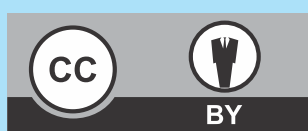

ORA 127

DOI: http://dx.doi.org/10.3126/bjhs.v4i2.25460

* Corresponding Author

Dr. Roshan Pradhan

Lecturer

Anaesthesia and Critical Care

Birat Medical College and Teaching Hospital Tankisinuwari, Nepal

Email ID: drroshanpradhan@gmail.com ORCID ID: http://orcid.org/0000-0002-0600-4446

\section{Citation}

Pradhan R, Mishra SK, Rajbanshi LK, Khanal K, Arjyal B, Pokharel HP. Effectiveness of Transversus Abdominis Plane Block for Postoperative Analgesia in Obstetric Cases Undergoing Caesarean Section. BJHS 2019;4(2)9: 755 - 758.

\section{ABSTRACT}

\section{Introduction}

Transversus abdominis plane (TAP) block is a regional anesthesia that involves the infiltration of local anesthetic in between the internal oblique and transversus abdominis muscle plane. This block provides post-operative analgesia and reduces the requirement of opioids consumption.

\section{Objective}

To assess the effectiveness of TAP block in providing postoperative analgesia in women undergoing caesarean section.

\section{Methodology}

This was a hospital based prospective, comparative, cross sectional study conducted in 70 patients from $17^{\text {th }}$ September 2018 to $17^{\text {th }}$ February 2019 undergoing caesarean section under spinal anesthesia. Patients were divided into two groups. Group A patients received TAP block with $0.5 \%$ Ropivacaine versus Group B patients received injection paracetamol 1gm intravenous every 8 hourly as a standard and routine analgesic. At the end of the surgery, TAP block was performed by anesthesiologist and assessment of postoperative pain using a visual analogue pain score at every 1 hour, 3 hour, 6 hour, 12 hour and 24 hour by trained staffs at postoperative ward. Then, depending upon the severity of the pain injection fentanyl $1 \mathrm{mcg} / \mathrm{kg}$ intravenous was given as rescue analgesia. Short assessment of patient satisfaction (SAPS) score was also assessed 24 hours postoperatively.

\section{Results}

Compared to control group, in women who received TAP block, there was statistically significant reduction in pain at 3 $\mathrm{hr}, 6 \mathrm{hr}, 24 \mathrm{hrs}$. However at $12 \mathrm{hrs}$ there was no significant difference in the pain score. The cumulative fentanyl requirement was also significantly less in the TAP block group at all the time points.

\section{Conclusion}

The TAP block provided highly effective postoperative analgesia following caesarean section and reduces the fentanyl requirement in the first 24 hour.

\section{KEYWORDS}

Caesarean section, transversus abdominis plane block, visual analogue scale. 


\section{INTRODUCTION}

The transverses abdominis plane (TAP) block is a commonly used peripheral nerve block where somatic nerves supplying the anterior abdominal wall is being anesthesized by deposition of local anesthetic at the site of transversus abdominis plane. ${ }^{1}$ The transversus abdominis plane is the fascial plane between the internal oblique and the transversus abdominis muscle containing the thoracolumbar nerves $T_{10}$ to $L_{1}{ }^{2}$ Local anesthetic agent deposited at this space results in myocutaneous sensory blockade. ${ }^{3}$ It is a regional anesthesia that has become increasingly popular over the last decade.

Nerve root or myofascial irritation at the abdominal wall is a common cause of pain following surgeries such as caesarean section, cholecystectomy, prostatectomy, hysterectomy and transplant surgery. ${ }^{4}$ The transversus abdominis plane (TAP) block is a regional block that provides adequate and effective postoperative analgesia in patients undergoing above surgery with midline infra-ubilical incision. ${ }^{2}$

This technique was first introduced in 2001 by Rafi as the one-pop technique. ${ }^{5}$ Later on, it was modified by McDonnell who described it as a "two pop" technique using regional anesthesia via a blunt needle perpendicular to the skin, just superior to the iliac crest and behind the mid-axillary line. ${ }^{5}$ The success rate of this technique is found to be around $85 \%$ among experienced practitioners. ${ }^{5}$ It has a high margin of safety and is technically easy to perform as seen in a study done at Massachusetts General Hospital, Boston, USA in 2012. ${ }^{6}$

TAP block can be given through lateral approach and the posterior approach however the difference in their efficacy regarding postoperative analgesia is still not clear. ${ }^{7}$

TAP block which is considered as multimodal analgesia will reduce the need of additional analgesics after surgery and reduces the severity of pain, prolong the demand for the first analgesic drug and improves patient's satisfaction during the postoperative period. ${ }^{3}$ It also modifies the surgical stress response which leads to a better outcome after surgery.

Pain following caesarean section has somatic (as a result of abdominal wall incision) and visceral (arising from the uterus) components. Postoperative pain after caesarean section is usually moderate to severe as described by the patients and failure to treat such pain may affect motherbaby bonding, care of the baby and breast feeding. ${ }^{8}$

The intensity of pain is a subjective phenomenon and may vary from person to person. Various scales have been used till date for post operative pain measurement where one of the most commonly used is Visual Analogue Scale (VAS). ${ }^{9}$ The patient is asked to mark his pain level on the line between the two endpoints. The distance between 'no pain at all' and the mark defines the subject's pain.

Although, the TAP block is relatively safe procedure, few cases of liver injury following needle insertion have been reported. Therefore, right sided TAP block following liver edge palpation as a land mark prior to needle insertion has been recommended to decrease such complications. Similarly, other less likely complication of this procedure like injury to peritoneal structures, transient femoral nerve block and local anesthetic toxicity. ${ }^{10}$ In order to minimize these complications, Hebbard et al. in 2007 had described an approach with ultra sound guided TAP block. ${ }^{11}$

Though majority of the cases with postoperative pain are managed with systemic or neuraxial opioids but they are associated with undesirable side effects like nausea, vomiting, pruritus, constipation and respiratory depression. NSAID'S alone may be insufficient to treat post caesarean pain. So, TAP block with $0.5 \%$ ropivacaine will have better analgesic efficacy for 24 hours after surgery. ${ }^{3}$

\section{METHODOLOGY}

This was a hospital based prospective, comparative, cross sectional study from $17^{\text {th }}$ September 2018 to $17^{\text {th }}$ February 2019, approved by the institutional review committee of Birat Medical College and Teaching Hospital (BMCTH). After informed written consent, 70 adult parturients belonging to American Society of Anesthesiologists physical status I and II requiring elective or emergency caesarean section were included in this double blind study whereas patients with $\mathrm{BMI}>=30 \mathrm{~kg} / \mathrm{m}^{2}$, with any contraindication to spinal anesthesia, who were unable to understand visual analogue scale (VAS), history of allergy to drugs used in the study and patients requiring general anesthesia for obstetric or anesthetic reason were excluded from the study.

Patients were randomly divided into two groups (group $A$ and group B) with each group consisting of 35 patients. Group A patients received TAP block with $0.5 \%$ Ropivacaine versus Group B patients received injection paracetamol $1 \mathrm{gm}$ intravenous every 8 hourly as a standard and routine analgesic. TAP block was performed by anesthesiologist and outcome was assessed by trained staff at postoperative ward. All patients had received intravenous (IV) ranitidine (50mg) and metoclopramide (10mg) preoperatively. Each patient received spinal anesthesia with $2-2.2 \mathrm{ml}$ of $0.5 \%$ heavy bupivacaine in sitting position after preloading with $500 \mathrm{ml}$ of Ringers lactate solution.

At the end of surgery, all patients of study group A received TAP block using landmark technique as described by McDonnell et al. ${ }^{5}$ The patients were kept in the supine position, the iliac crest was palpated and Triangle of Petit was located (anteriorly bounded by external oblique muscle and posteriorly by latissimus dorsi muscle and inferiorly by iliac crest). 18 gauge blunted tip needle was inserted in the triangle of Petit above the iliac crest at right angle to the coronal plane until resistance was felt. The needle was advanced gently in the same direction until "pop" sensation was felt, which signaled entry into facial plane between external and internal oblique muscles. Further advancement resulted in $2^{\text {nd }}$ "pop" and this indicated entry into TAP. After 
careful negative aspiration $20 \mathrm{ml}$ of $0.25 \%$ ropivacaine was injected slowly. The block was given on the other side using the same method.

Postoperative pain was assessed using a visual analogue scale (VAS). It has been classified as no pain (0), Mild pain (1-2), Moderate pain (3-7), Severe pain (7-10). Then postoperative pain was assessed every 1 hour, 3 hour, 6 hour, 12 hour and 24 hour. Pain score was compared between both groups. Then depending upon the severity of the pain injection fentanyl $1 \mathrm{mcg} / \mathrm{kg}$ intravenous was given as rescue analgesia. Short assessment of patient satisfaction (SAPS) was also assessed 24 hours postoperatively. It is subjectively measure as very satisfied (0), satisfied (1), neither satisfied nor dissatisfied (2), dissatisfied (3), very dissatisfied (4).

The significance test was done in 95\% Confidence interval and $80 \%$ power of study. The previous study by Srivastava et al showed use of TAP block reduced analgesic requirement by $50 \%{ }^{2}$ We assumed that $75 \%$ of decrease in analgesic requirement will provide significant outcome.

\section{Considering $10 \%$ as dropout, the sample size was calculated as 70 .}

Sample size $=2\left(Z_{\alpha} \quad\right)^{2} P(1-P) /\left(P_{1}-P_{2}\right)^{2}$

$Z_{\alpha / 2}=Z_{0.05 / 2}=Z_{0.025=} 1.96$ (from $Z$ table) at type l error of $5 \%$

$Z_{\beta}=Z_{0.20}=0.842$ (From $Z$ table) at $80 \%$ Power

$\mathrm{P}_{1}-\mathrm{P}_{2}=$ Difference in proportion of events in two groups

$\mathrm{P}=$ Pooled prevalence $=\left[\right.$ prevalence in case group $\left(\mathrm{p}_{1}\right)+$ prevalence in control group $\left.\left(p_{2}\right)\right] / 2$

Data was entered in MS excel and analyzed by IBM SPSS version 23.

Continuous data was presented as mean and standard deviation while categorical data was presented as the frequency and percentage. Significance was tested using fisher's exact test.

A p value of $<0.05$ will be considered as significant.

\section{RESULTS}

A total of 70 patients who fulfilled the inclusion criteria were enrolled for this study where group $A(n=35)$ had received TAP block and group $B(n=35)$ had received injection paracetamol 1gm intravenous 8 hourly as a standard and routine analgesic. Pain was assessed every 1, 3, 6, 12 and 24 hour via Visual Analogue Scale (VAS). Pain score was compared among those groups. Then, depending upon the severity of the pain injection fentanyl $1 \mathrm{mcg} / \mathrm{kg}$ intravenous was given as rescue analgesia. The two groups were similar in terms of demographic and other data. (Table 1)w

\begin{tabular}{|c|c|c|c|}
\hline Variables & Group A & Group B & P value \\
\hline Age (y) & $25.03 \pm 4.78$ & $24.2 \pm 4.575$ & 0.461 \\
\hline Weight (kg) & $58.86 \pm 9.762$ & $59.31 \pm 8.814$ & 0.838 \\
\hline Duration of Surgery (min) & $29.71 \pm 11.307$ & $30 \pm 6.966$ & 0.899 \\
\hline
\end{tabular}

$\begin{array}{clllr}\begin{array}{c}\text { Table 2: VAS Scoring } \\ \text { Time }\end{array} & \text { Pain variable } & \begin{array}{l}\text { Group 1 } \\ \text { (N= 35) }\end{array} & \begin{array}{l}\text { Group 2 } \\ \text { (N=35) }\end{array} & \text { P value } \\ 1 \mathrm{hr} & \text { No pain } & 35(100 \%) & 35(100 \%) & \text { NA } \\ 3 \mathrm{hr} & \text { No pain } & 34(97.1 \%) & 19(54.3 \%) & \\ & \text { Mild pain } & 0(0.0 \%) & 3(8.6 \%) & 0.000^{*} \\ & \text { Moderate pain } & 0(0.0 \%) & 13(37 \%) & \\ & \text { Severe pain } & 1(2.86 \%) & 0(0.0 \%) & \\ 6 \mathrm{hr} & \text { No pain } & 30(86 \%) & 19(54.2 \%) & \\ & \text { Mild pain } & 0(100 \%) & 3(8.6 \%) & 0.008^{*} \\ & \text { Moderate pain } & 2(5.71 \%) & 10(28.6 \%) & \\ 12 \mathrm{hr} & \text { Severe pain } & 3(8.6 \%) & 35(100 \%) & \\ & \text { No pain } & 28(80 \%) & 24(68.6 \%) & 0.720 \\ & \text { Mild pain } & 2(5.71 \%) & 4(11.42 \%) & \\ & \text { Moderate pain } & 3(8.52 \%) & 5(14.3 \%) & \\ 24 \mathrm{hr} & \text { Severe pain } & 2(5.71 \%) & 2(5.71 \%) & \\ & \text { No pain } & 25(71.42 \%) & 6(17.14 \%) & \\ & \text { Mild pain } & 2(5.71 \%) & 6(17.14 .0 \%) & 0.000^{*} \\ & \text { Moderate pain } & 5(14.2 \%) & 21(60 \%) & \\ & \text { Severe pain } & 3(8.6 \%) & 2(14.2 \%) & \end{array}$

\begin{tabular}{|c|c|c|c|}
\hline \\
\hline \multicolumn{4}{|c|}{ Table 3: Rescue analgesia } \\
\hline Variables & $\begin{array}{l}\text { Group } 1 \\
(\mathrm{~N}=35)\end{array}$ & $\begin{array}{l}\text { Group } 2 \\
(n=35)\end{array}$ & P value \\
\hline $\begin{array}{l}\text { Number of patients } \\
\text { requiring rescue an }\end{array}$ & $\begin{array}{l}22(62.9 \%) \\
\text { esia }\end{array}$ & 34 (97.14\%) & 0.000 \\
\hline
\end{tabular}

\begin{tabular}{|c|c|c|c|}
\hline \multicolumn{4}{|c|}{ Table 4: Total dose } \\
\hline Variable & Group 1 & Group 2 & P value \\
\hline Total dose & $31.42 \pm 24.51$ & $102.85 \pm 38.23$ & $0.000 *$ \\
\hline
\end{tabular}

* Statistically significant

\begin{tabular}{llll}
$\begin{array}{l}\text { Table 5: SAPS score } \\
\text { Variables }\end{array}$ & $\begin{array}{l}\text { Group 1 } \\
(\mathbf{N}=35)\end{array}$ & $\begin{array}{l}\text { Group 2 } \\
(\mathbf{N}=35)\end{array}$ & P value \\
$\begin{array}{l}\text { Very satisfied (0) } \\
\text { Satisfied (1) }\end{array}$ & $\begin{array}{l}11(31.42 \%) \\
1(2.9 \%)\end{array}$ & $0.000^{*}$ \\
$\begin{array}{l}\text { Nor satisfied } \\
\text { nor dissatisfied (2) }\end{array}$ & $1(2.9 \%)$ & $22(62.8 \%)$ & \\
\hline
\end{tabular}

* Statistically significant

None of the patients in either group had postoperative pain at 1 hour due to regional spinal anesthetic effect. Therefore, pain at 1 hour was not comparable. Pain scores were found to be reduced in patients who had received TAP block at 3, 6 and 24 hours postoperatively as compared to the control group. However, at 12 hours there was no significant difference in the pain score.

In patients receiving TAP block with $0.5 \%$ ropivacaine (Group A), the requirement for rescue analgesic over 24 hours postoperative period was significantly reduced as compared to those who received injection paracetamol (Group B) (Table 3).

Similarly, patients receiving TAP block (Group A) had better satisfaction when compared to control group (Group B) as shown by Short assessment of patient satisfaction (SAPS) score (Table 5).

\section{DISCUSSION}

Postoperative pain management following caesarean section is challenging. Thus, the analgesic regimen for postoperative period should be effective, safe and devoid of 
any side effects. Use of systemic opioid analgesia in postoperative period can result in adverse effects like nausea, vomiting, pruritus, constipation and respiratory depression. ${ }^{12}$ Moreover, NSAID'S alone may be insufficient to treat post caesarean pain. ${ }^{13}$ Adequate postoperative analgesia leads to reduction in the postoperative stress response, improved patient comfort, surgical outcome and also accelerates recovery from surgery. ${ }^{14}$

TAP block as introduced by Rafi et al. for the first time by injecting a local anesthetic agent using anatomical landmark (iliac crest) by identifying the lubar triangle of Petit. He concluded that it provided better postoperative analgesia in lower abdominal surgery. ${ }^{15}$ Though, Rafi's landmark technique had shown the risk of complication like visceral organ injury, injection into superficial circumflex iliac artery and femoral nerve injury but in presents study no such complication were found with this block.

In our study, 24 hours postoperative opioids consumption was significantly reduced which was similar to study shown by Srivastava et al. and Mankikar et al. ${ }^{2,3}$

Similar results were noticed in a cochraine database study by Charlton et al. in 2010 where TAP block had resulted in significantly less postoperative opioid consumptions at 24 hours compared with no TAP block or saline (placebo). ${ }^{16}$

This study had also shown that patients receiving TAP block had reduced early post-operative visual analogue scores (VAS) at rest which was similar to the findings as concluded by Petersen et al. and Mankikar et al.'

Various randomized clinical trials had shown the clinical efficacy of TAP block in adults undergoing lower abdominal surgeries. Most of them showed the effectiveness of TAP block by reduction in the need of postoperative rescue analgesia, lowering the pain scores and reduction in opioid induced side effects. ${ }^{17}$ Similarly, following TAP block there was significant reduction in the postoperative fentanyl consumption, lowering of pain scores and no side effects as demonstrated by present study.

The present study demonstrates TAP block with $0.5 \%$ ropivacaine provided effective postoperative analgesia, significantly reduced post operative opioid consumption

\section{REFERENCES}

1. Bhattacharjee S RM, Ghose T, Maitra S, Layek A. Analgesic efficacy of transversus abdominis plane blockin providing effective perioperative analgesia in patientsundergoing total abdominal hysterectomy: A randomizedcontrolled trial.JAnaesthesiol Clin Pharmacol 2014;30(3):391-6.

2. Mankikar MG SS, Ghodki PS. Ultrasound-guided transversus abdominis plane block for post-operative analgesia in patients undergoing caesarean section. Indian J Anaesthesiol Clin Pharmacol. 2016;60(4):253-7.

3. Srivastava U VS, Singh TK, Gupta A, Saxsena A, Jagar KD, et al. Efficacy of trans abdominis plane block for post cesarean delivery analgesia: A double-blind, randomized trial. Saudi journal of anaesthesia. 2015;9(3):298-302.

4. Ma N DJ, Scarfe AJ, Schuhmann S, Cameron AL. Clinical safety and effectiveness of transversus abdominis plane (TAP) block in postoperative analgesia: a systematic review and meta-analysis. Journal of anesthesia. 2017;31(3):432-52.

5. Kahsay DT EW, Bahta HZ. Transversus abdominis plane block after Caesarean section in an area with limited resources. 2017;23(4): 90-5.

6. Young MJ, Gorlin AW, Modest VE, Quraishi SA. Clinical implications of the transversus abdominis plane block in adults. Anesthesiology research and practice. 2012;2012:731645.

7. Yoshiyama S UH, Sakai R, Otake H. A Posterior TAP Block Provides More Effective Analgesia Than a Lateral TAP Block in Patients Undergoing Laparoscopic Gynecologic Surgery: A Retrospective Study. Anesthesiology research and practice. 2016;2016:4598583. and improved pain score. Moreover, SAPS were also significantly reduced $(p=<0.001)$ in group $A$ compared to group $B$ in present study. Reduction of twenty four hours fentanyl requirement in this study demonstrates that TAP block can produce adequate and effective postoperative analgesia. So, TAP block can be an important tool in managing postoperative analgesia in women undergoing caesarean section.

\section{CONCLUSION}

We concluded that the TAP block with $0.5 \%$ ropivaciane provided highly effective postoperative analgesia following caesarean section and reduces the fentanyl requirement in the first 24 hours and no complications with TAP block were detected.

\section{RECOMMENDATIONS}

We recommend TAP block with $20 \mathrm{ml}$ of $0.25 \%$ ropivacaine on each side at the end of the surgery provides effective postoperative analgesia and reduces the opioids requirement in the first 24 hour.

\section{LIMITATION OF THESTUDY}

Only caesarean sections were involved. Use of real time USG for TAP block is increasing; we used landmark anatomic approach.

\section{ACKNOWLEDGEMENT}

We would like to acknowledge all respondents, postoperative ward staff, seniors and my family for their support, time and participation, without them this study wouldn't have been possible.

\section{CONFLICT OF INTERST}

We declare no conflict of interest.

\section{FINANCIAL DISCLOSURE}

Nil.

8. Raghvendra KP TD, Mitra S, Ahuja V, Gombar S, Huria A. Postoperative pain relief following hysterectomy: A randomized controlled trial. J Mid-life Health. 2016;7:65-8.

9. Hawker GA MS, Kendzerska T,French M. Measures of Adult Pain. American College Of Rheumatology. 2011;63:240-52.

10. Mrunalini P RRN, Nath VN, Saheb SM. Efficacy of transversus abdominis plane block in patients undergoing emergency laparotomies. Anesth Essays Res Brief. 2014;8:377-82.

11. PD Hebbard YF, Y Shibata, CF Royse. Ultrasound-guided transversus abdominis plane (TAP) block. Anaesthesia and intensive care. 2007;35(4):616-7.

12. Chen $Q A R$, Zhou J, Yang B. Clinical analgesic efficacy of dexamethasone as a local anesthetic adjuvant for transversus abdominis plane (TAP) block: A meta-analysis. PloS one. 2018;13(6):e0198923.

13. Joris J. Efficacy of nonsteroidal antiinflammatory drugs in postoperative pain. Acta Anaesthesiol Belg. 1996;47(3):115-23.

14. Bonnet F ME. Influence of anaesthetic and analgesic techniques on outcome after surgery. British journal of anaesthesia. 2005;95:52-8.

15. AN R. Abdominal field block: a new approach via the lumbar triangle. 2001;56(10):1024-6.

16. S. Charlton AMC, P. Middleton, and J. D. Griffiths. Perioperative transversus abdominis plane (TAP) blocks for analgesia after abdominal surgery. Cochrane Database of Systematic Reviews. 2010;8. 